\title{
A Cognitive Approach to the Metaphors of Postpartum Depression in Elif Shafak's Black Milk
}

\author{
Yasir A. Al-Jumaili', Shaymaa F. Hasan², Safeen N. Arif ${ }^{3}$ \\ 1,2,3 Department of English Language, Faculty of Humanities and Social Sciences, Koya University, Kurdistan Region, Iraq
}

\begin{abstract}
Despite the fact that postpartum depression has been explicitly referred to in Elif Shafak's novel Black Milk (2007), there are many implicit references to this negative mental state. This paper aims to examine the metaphorical representations which are used to conceptualize the experience of postpartum depression. The study attempts to understand how the experience of postpartum depression is metaphorically constructed and conveyed via the use of conceptual metaphors. This study differs from previous studies which examined Shafak's Black Milk; the current study attempts a cognitive approach to its metaphorical language. The study applies insights from Conceptual Metaphor Theory (CMT) by George Lakoff and Mark Johnson $(1980 ; 2003)$ to selected metaphors from Shafak's novel Black Milk. The study is the first of its kind; it offers a stylistic examination of the metaphors of postpartum. The application of conceptual metaphor theory, in our opinion, serves as a useful tool that allows better understanding of how the abstract state of postpartum depression is understood and communicated through the course of the novel. The study also discusses the cross-domain mapping process to see how conceptual structures are selected from different source domains and mapped onto the target domain of postpartum depression to unveil the negative effects of this distressing experience.
\end{abstract}

KEY WORDS: Conceptual Metaphor Theory, Cross-Domain Mapping, Depression, Elif Shafak, Postpartum

\section{INTRODUCTION: Postpartum Depression and} Literature

Before starting the analysis of metaphors of postpartum depression, it is very important to define the term and its implications. 'Postpartum depression' is a term that refers to a psychological (or emotional) state of mind experienced by women after child birth. This mental state has many consequences such as the personal suffering of women as well as social and cognitive development of mother-child relationship (Murray and Cooper 1999, 3). It is one of the variants of depression that is known by its severe symptoms that

Koya University Journal of Humanities and Social Sciences (KUJHSS), Volume 4, Issue 1, 2021.

Received 29 Jul 2020; Accepted 26 Aug 2020,

Regular research paper: Published 30 Jun 2021

Corresponding author's e-mail: yasir.jumaily@koyauniversity.org

Copyright (02021. Yasir A. Al-Jumaili, Shaima F. Hassan,

Safeen N. Arif, this is an open access article distributed under the Creative Commons Attribution License. can cause dangerous mood swings; excessive crying, social withdrawal (from family and friends), insomnia or excessive sleep, lack of interest or pleasure in usual activities, feelings of hopelessness or helplessness, fear, lack of concentration, weak memory, paranoia and hallucinations. Normally these symptoms develop during the first week after delivery and can be very harsh (Wikipedia Contributors "Postpartum depression", 2020).

As far as literature is concerned, there is a relatively huge amount of research conducted to show the impact and the consequences of postpartum depression on victims. The representation of postpartum has been the main task of many writers and critics as well. Shafak's Black Milk is one of the best examples that show the projection of postpartum on female figures. The novel is an autobiographical account in which the writer conveys her own spiritual pre / post-marital concerns. Shafak appears as a central female character who suffers different phases of postpartum depression. Following her marriage and with the arrival of her daughter Zelda, Shafak was diagnosed of postpartum depression. She 
was affected by her negative mental state which deprives her of her talent of writing. Her suffering became evident in her novel Black Milk; she spoke about her struggle with this disease. She identifies the following signs as symptoms of postpartum depression, they include:

"lack of energy, excessive sensitivity and irritability, feeling guilty or inadequate, inability to focus, forgetfulness, a fear of hurting yourself or the baby, irregular sleep patterns, lack of appetite, lack of sexual drive, antisocial behavior (closeting yourself in the house, avoiding people and even close friends), lack of interest in physical appearance, an ongoing indifference toward the rest of the world..." (Shafak, p. 238).

Another sign of Elif's postpartum depression is "worrying too much", which she believes "comes with thinking" (Shafak, p. 212). She also feels haunted by horrible visions which cause a sense of incompetency, lack of self-confidence, loss and uncertainty as well as a sense of alienation as if she lives "in a world that increasingly feels foreign" (Shafak, p. 215). This, eventually, leads her to draw a gloomy conclusion; she "cannot even talk to God anymore" (Shafak, p. 217). She becomes a victim of her foreboding feelings of despair and inefficacy owing to the disappearance of the last source of hope, which is her connection to God: "Is that what depression is about - the sinking feeling that your connection to God is broken and you are left to float on your own in a liquid black space, like an astronaut who has been cut loose from his spaceship and all that linked him to Earth?" (Shafak, p. 220). In this way, she is like a straw flung by winds in a stormy day.

In this paper, the main focus is on the metaphorical representation of postpartum depression. The use of metaphors helps writers and readers to grasp the meaning of complex states such as mental or emotional experiences. As far as the author is concerned, Shafak relies on the use of metaphoric language to express her understanding of postpartum in an easy and effective way. As a model for the analysis, the paper uses the current view of metaphor - Conceptual Metaphor Theory (CMT) - which was promoted by George Lakoff and Mark Johnson in their book Metaphors We Live By (1980). A further discussion of this methodology will be presented in the following section.

\section{METHODOLOGY}

The idea that metaphor is a cognitive phenomenon has replaced the traditional view which considered metaphor as a linguistic tool. This current view of metaphor is widely accepted in many fields of literary, linguistic and cognitive studies (Semino, 2008; Semino \& Demjén, 2017; Kövecses, 2017). The current view of metaphor is first developed by two linguists, George Lakoff and Mark Johnson in their seminal book, Metaphors We Live By (1980). They proposed a new framework to reason about metaphorical language which is known later as Conceptual Metaphor Theory (CMT). The gist of their framework is that metaphor comprises two conceptual domains. The first domain is called 'source domain' from which all conceptual structures are borrowed, and the second is called 'target domain' to which all the conceptual structures are transferred (mapped). As Lakoff and Johnson argue, we understand the target domain in terms of the source domain through a process known as cross-domain mapping (Lakoff and Johnson 1980). They claim that the target domain is usually an abstract and unfamiliar to us; therefore, we view it or understand it through the help of the source domain which is usually concrete and more familiar to us. The source domain, according to their viewpoint, is based on our daily experiences and interactions with the world around us. Thus, comparing things which are less familiar with thigs that are more familiar facilitates our understanding of the former via the latter. This new framework offers a new logic about figurative language; it views metaphor as "understanding and experiencing one kind of thing in terms of another" (Lakoff and Johnson 2003,5).

Conceptual metaphor theory, therefore, is a departure from the traditional approach which is based on the classical distinction between the literal and figurative language. CMT challenges the main assumption that everyday language is mainly literal and all subject matters can be understood literally without any need for metaphors (Searle 1979; Davison 2006). According to the current approach, metaphors work on the conceptual level, and human conceptual system is not literal, it is metaphorical in nature. Lakoff and Johnson even argue that metaphor is not a mere linguistic or ornamental rhetorical device as traditionally thought by Aristotle and his followers. For Lakoff and Johnson, metaphor is central to thought and it is a conceptual phenomenon (Lakoff \& Johnson 1980; Lakoff 1993; Kövecses 2005). Conceptual metaphor is very fundamental in understanding complex things, they state that "much subject matter, from the most mundane to the most abstruse scientific theories can only be comprehended via metaphor" (Lakoff and Johnson 1980, 244). Thus, this framework can help understanding many abstract concepts and notions such as emotional and mental states like depression and other negative states because it allows comparing them to more familiar experiences that belong to other domains of knowledge.

The central claim of CMT is that the way we think and view things is shaped and controlled by metaphors, i.e., we think and understand things in terms of other things which are more familiar to us. According to the advocate of this framework, the knowledge provided by the source domain plays an important and crucial role in understanding of the target domain (Zlatev, Andrén and 
Falck 2009, 230). Lakoff and Johnson believe that metaphors should not be seen as words or phrases but as "sets of conceptual correspondences" (Lakoff and Johnson 1999, 207). Moreover, they theorize that a conceptual metaphor underpins many linguistic expressions which can be seen as linguistic realizations for that conceptual metaphor. For example, linguistic expressions such as I am up, or She is above clouds and $\mathrm{He}$ is on cloud nine can be considered as linguistic realizations which are underpinned by a conceptual metaphor HAPPY IS UP. Similarly, expressions like I feel down and He let me down or She brought me down with her words can be seen as linguistic realizations of the conceptual metaphor SAD IS DOWN.

As far as function is concerned, conceptual metaphors are classified into three types: structural metaphors, ontological metaphors and spatial metaphors. As they argue, structural metaphors help human beings structure their understanding of one thing in terms of something else. In this type of metaphor, the source domain provides schematic information (basic knowledge or conceptual structures for the target domain. Thus, the target domain is understood or viewed through conceptual structures mapped from the source domain (Kövecses 2002, 33). The use of the expression Argument is War in which our understanding of the target domain of 'argument' is structured in terms of our understanding of the source domain of 'war' can serve as a good illustration of this claim.

The second type of conceptual metaphor is called ontological metaphor "which are based on our experiences of physical objects and substances" (AlJumaili 2018, 48). Ontological metaphor involves applying physical quality or concrete element borrowed from a source domain onto a target domain. For example, we understand abstract states in terms of physical or concrete objects as in the following sentence he broke his silence or he swallowed his words. The abstract notions of 'silence' and 'words' are presented in terms of physical objects which can be broken and swallowed.

The third kind of conceptual metaphor is known as spatial or orientational metaphor. In this type, the two domains (source and target) are compared spatially through orienational positions. For instance, the sentence he fell ill, illustrates our understanding of sickness in terms of a spatial orientation, such as sick is down, bad is down or happy is up and good is up. Such spatial orientations can underpin many linguistic metaphors such as "I'm feeling down" or "the news boosted my spirit" (Kövecses 2002,36).

As already mentioned above, the paper applies insights from Conceptual Metaphor Theory to a selection of metaphorical expressions about postpartum depression taken from Shafak's Black Milk. CMT can help understand metaphors of postpartum depression in a better and convenient way; it provides a new reading of the novel in regard to its metaphorical language.

\section{ANALYSIS}

In order to describe a "complex phenomenon" and mental states such as postpartum depression, victims of such states usually use "figurative language" such as "metaphors and metonymy" because these emotional and mental states are very complex to be literally stated or described (Lakoff and Johnson 1999; Kövecses 2000; Meier and Robinson 2005; Demjén 2010). In Shafak's novel there is plenty of conceptualization of the experience of postpartum depression which was suffered by the poetic voice (narrator). For reasons of space, only selected metaphors are chosen for analysis in this paper. A detailed examination of the metaphors of postpartum depression can be conducted in another research project longer than this journal article such as a thesis or dissertation.

The analysis will be divided into different parts; each part deals with a specific set of conceptualization. To start with the first set, postpartum depression is conceptualized in terms of a place. The novel contains examples where the abstract experience of postpartum depression is represented in terms of a physical location which is characterized by negative valance and connected with negativity. The first example of conceptualizing postpartum depression as a physical place occurs at the beginning of the novel where the writer provides notes to her readers about her experience with this negative and depressive state. She clearly states that "when the postpartum depression hit, it caught me completely unguarded. Stretching out in front of me like a dark tunnel that seemed to have no end" (Shafak, p. xi). Although the term 'postpartum' is explicitly mentioned, the extract has an interesting metaphor to represent the negative state of postpartum depression. The metaphorical idea is performed through comparing postpartum to 'dark tunnel' that has no end. Literally speaking, postpartum depression is a negative mental state that affects women only; it is not something familiar to all readers. Therefore, the speaker uses the prior knowledge of a 'tunnel' to communicate the effects of this negative mental state to the reader. The noun phrase 'dark tunnel' serves as a source domain that provides conceptual structures to reason about postpartum depression. The source domain activates a physical scenario in which an agent is situated in a dark place. Through mapping process, the speaker becomes able to describe something of abstract quality (postpartum depression) through another domain that has a concrete and physical quality (tunnel). In other words, by running the cross-domain mapping, it 
becomes possible to view the abstract state of postpartum depression as a dark tunnel which extends to no end. The speaker maps selected information such as narrowness, endless, darkness and absence of vision from the source domain of 'dark tunnel' onto the target domain of postpartum depression. Moreover, the 'dark tunnel' generates another negative state which is the state of darkness that denotes fear, dimness, and lack of vision as well as loss of directionality. It contributes a physical scenario where the speaker is stuck in an unpleasant and hazardous place. As a result of the crossdomain mapping, the experience of postpartum depression has acquired new constructed meaning which was not available before running the mapping process. The use of conceptual mapping helps both speaker and reader to understand something less familiar and of an abstract quality through domains that are more familiar and have concrete quality. It becomes possible to see the experience of having postpartum depression as someone moving in a dark place. It is possible to say that Shafak's metaphorical expression above involves similar mapping contained in the conceptual metaphors of A MENTAL STATE IS A PHYSICAL OBJECT (Yu 2008, 258), STATES ARE LOCATIONS (Lakoff and Johnson 1999, 194), and DEPRESSION IS DARKNESS (McMullen and Conway 2002, 168).

A similar metaphorical expression occurs toward the end of the novel when the experience of postpartum depression is conceptualized in terms of 'a roundabout of gloom'. In the following extract, Shafak describes victims who suffer from such a negative mental state as spending their life in a gloomy place, she states that "people who are depressed have very little contact with the present moment ... they are stuck in a roundabout of gloom" (Shafak, p. 234). This expression is very similar to the previous one; postpartum depression is also represented through the domain of physical location (place). The noun phrase 'roundabout of gloom' can serve as a source domain through which readers can understand the abstract experience of postpartum depression in a concrete way, i.e., as a roundabout characterized by gloominess. This expression is metaphorically used because the speaker is not talking about an actual roundabout; she speaks of a mental state that has a negative valence on her. The abstract experience of postpartum depression is a different entity from the physical location of roundabout. Through the process of cross-domain mapping, it becomes possible to view the target domain of 'postpartum depression' through the source domain of 'roundabout of gloom'. As mentioned in the methodology section above, our prior knowledge of the source domain helps us understand the target domain in a better way. The speaker maps conceptual structures such as circuitous route, never ending movement or indirect way from the source domain of 'round about' onto the target domain of postpartum depression. Moreover, the semantic item of 'gloom' contributes a sense of darkness and dismal atmosphere to the process of conceptualization. Therefore, the outcome of the cross-domain mapping is that, the experience of postpartum depression is communicated through a physical scenario in which an agent is going through a roundabout of gloom. The similarity between the two compared domains is that, as going through a gloomy roundabout might go endless, having postpartum depression can persist for a long line. Shafak's metaphorical expression can be seen as a linguistic realization of the following conceptual metaphors A MENTAL STATE IS A PHYSICAL OBJECT (Yu 2008, 258), STATES ARE LOCATIONS (Lakoff and Johnson, 1999: 194), DEPRESSION IS DARKNESS (McMullen and Conway 2002, 168), and (SAD IS DARK) (Kövecses 2000, 25).

The novel features other examples of describing postpartum depression through physical place. For example, the experience of postpartum depression has been represented in terms of "a sea without a shore" (Shafak, p. 209). In this noun phrase, the speaker tries to communicate the inner fear and sufferings of her experience with postpartum depression by comparing herself to a ship that endlessly sails in a sea that has no shores. As we have already said, sufferers of complex states rely on metaphors to talk about these states. The phrase "a sea without a shore" is used metaphorically, because literally, postpartum depression is not a sea, and in reality there is no sea without a shore. Thus, the term 'sea' in this phrase can be considered as a source domain from which conceptual structures are mapped onto the target domain of postpartum. The crossdomain mapping is run between the source domain of sea from which schematic information or conceptual structures such as being wide, big, huge, deep, dangerous are mapped onto the target domain of postpartum depression. Thus, since we are more familiar with the concept of sea, it becomes easier to understand the abstract state of postpartum depression through comparing it to a sea. As a result of crossdomain mapping process, a new meaning of postpartum depression is constructed; it becomes infinite like going on a sea without a shore. As the sea without a shore has no limits, postpartum depression, on the other hand, can also be endless. The metaphorical expression 'a sea without a shore' can be seen as a linguistic realization inspired by the conceptual metaphor EMOTION IS LOCATION (Gibbs 2005, 9) and STATES ARE LOCATIONS (Lakoff and Johnson 1999, 194).

The fourth example in this set of conceptualization occurs at the end of the novel where the negative state of postpartum depression is represented in terms of a 
damp place. In the following extract, Shafak compares her experience with postpartum depression to being stuck in a 'quagmire', she states that "I urgently had to go back to writing to find my way out of this quagmire" (Shafak, p.250). The speaker wants to communicate the feeling of being unable to move on or restore her normal life after being attacked by postpartum depression. The term 'quagmire' can be considered as a source domain to describe the target domain of postpartum depression. Literally, the speaker does not refer to an actual quagmire; she describes an emotional or mental state of being hindered by a psychological obstacle that she wants to overcome. She wants to restore her normal life through writing which can help getting out of this quagmire (postpartum depression). Conceptually, the cross-domain mapping is performed between the source domain of quagmire and the target domain of postpartum depression. Through the mapping process, selected conceptual structures such as stagnant, predicament, hazardous situation, muddy, boggy, dirty are mapped from the source domain onto the target domain. As a result of this cross-domain mapping, the abstract state of postpartum depression acquires a new constructed meaning; postpartum depression can now be understood in terms of a quagmire. The analogy between the two different domains is that, as quagmire denotes unpleasant place or situation that is difficult to get out of, postpartum is also an unpleasant experience that is difficult to get rid of. The linguistic expression "to find my way out of this quagmire" is the linguistic realization of the conceptual metaphors of STATES ARE LOCATIONS (Lakoff and Johnson 1999) and STATES ARE BOUNDED REGIONS (Petruck 2018).

Having looked at some examples of conceptualizing postpartum depression as a place, our analysis moves to discuss another set of metaphorical expressions in which postpartum depression is represented in terms of a physical object. The following examples demonstrate how the source domain of physical object is conceptually and linguistically employed to reason about the abstract state of postpartum depression. This negative mental state is viewed physically via mapping conceptual structures from the domain of concrete objects. Cognitive linguists call the process of mapping from the domain of physical objects as 'reification' (Sfard 1994; Goschler 2007). Reification is used to ascribe physical features for some abstract states, in other words, it adds "a sense of concreteness to an abstract phenomenon" (Al-Jumaili 2018,175).

The first example of objectifying postpartum depression occurs in the first chapter, when the speaker comments on the idea that no woman is "immune to postpartum blues" (Shafak, p.9). She goes on to state that, "interestingly, this psychological roller coaster can happen just as easily with the second, the third or even the sixth pregnancy as with the first" (Shafak, p. 9). In this expression, there is a direct comparison between the mental state of postpartum depression and the 'roller coaster'. It is obvious that the speaker is talking metaphorically, because literally, postpartum depression and roller coaster are two different entities that belong to different domains. The noun phrase 'roller coaster' is used as a source domain from which we can map selected conceptual structures that enable us to understand the abstract state of postpartum depression as a moving physical object, i.e., a psychological roller coaster. Conceptually speaking, the cross-domain mapping is performed between the source domain of roller coaster and the target domain of postpartum depression. Selected conceptual structures such as being scary, fast and sudden move, having tight turns and steep slopes, having dramatic changes and causing fear are mapped from the source domain onto the target domain. The outcome of the cross-domain mapping has generated a new constructed meaning of the negative state of postpartum depression. It can be viewed concretely as a moving roller coaster. In other words, the speaker uses his prior knowledge of the roller coaster which is more familiar and has physical qualities to describe something less familiar and has abstract qualities. As a result, we can view the less familiar through the more familiar or the abstract through the concrete. It is possible to argue that, in creating her linguistic expression of "psychological roller coaster", the speaker is motivated by the conceptual metaphors of A MENTAL STATE IS A PHYSICAL OBJECT (Yu 2008), ABSTRACT IDEAS AS OBJECTS (Górska 2019), and STATES ARE OBJECTS (Kövecses 2017). These conceptual metaphors offer a conventional method to talk about abstract phenomena in terms of physical and concrete objects.

The second interesting example occurs in another chapter in which Shafak talks about her experience of postpartum depression in terms of a computer that is not functioning properly. She states that "my mind acts like a computer gone awry" (Shafak, p.40). In this expression, the speaker, metaphorically, compares her state of mind with a computer that is not functioning well. Literally speaking, the speaker's mind is not a physical entity; it is an abstraction that cannot be seen or touched. Therefore, the expression is said in a metaphorical context in which the comparison is held between the abstract state caused by postpartum depression and a physical object of a computer. The speaker uses her prior knowledge of computers to communicate an abstract state or a phenomenon. The term 'computer' serves as a source domain that provides conceptual frames or structures that can be used to reason and think of postpartum depression. Schematic information such as computing, processing and storing 
data, calculating and solving problems are mapped from this physical source domain on the target domain of postpartum depression. As a result of the cross-domain mapping, the abstract state of postpartum depression acquires a new constructed meaning; it is viewed in a physical way as a computer that has deviated from the expected way of performance. The cross-domain mapping activates a physical scenario in which an agent (the speaker) is suffering from a mental problem that hinders him from thinking and behaving in a proper way. This situation is best illustrated through the comparison between the speaker's mind, which is the center of mental activities, and a malfunctioning computer. To create the above mentioned metaphorical expression, the speaker relies on the following conventional metaphors such as DEPRESSION IS A LACK OF VITALITY, DEPRESSION IS LACK OF CONTROL (Pritzker 2003) and SADNESS IS A LACK OF VITALITY (Kövecses 2005). He extends and linguistically elaborates these conceptual metaphors to create his own ones.

The third example in this set can be found in a chapter entitled "A Sea without a Shore" where the speaker compares herself to a 'sinking ship'. We have already discussed the metaphorical expression of 'a sea without a shore" in which the experience of postpartum depression is represented as a place (location). Now, we discuss the representation of this negative state in terms of a physical object (sinking ship). In her early days as a new mother, the speaker states that "I am sliding to one side, like a sinking ship" (Shafak, p.209). In this expression, she compares her situation as a mother to a sinking ship; she does not know how to control this new situation or even to cope with it. The experience of having postpartum depression is compared to a disastrous situation of a ship sinking into a sea. The noun phrase 'sinking ship' can be considered as a source domain that provides conceptual structures that enable the speaker to talk about something abstract in terms of a concrete object. The speaker uses her prior knowledge or (schematic information) of sinking ship to describe a phenomenon of abstract qualities like postpartum depression. Through the process of cross-domain mapping, conceptual structures such as descending and dropping down or a huge body or an object going down or becoming submerged under or below a water surface are mapped from the source domain of 'sinking ship' onto the target domain postpartum depression. The outcome of this conceptual mapping is that postpartum depression has acquired a new meaning; it becomes possible to understand it in a concrete way (as a sinking ship). This metaphorical expression can be viewed as a linguistic realization of the conceptual metaphors of DEPRESSION IS DOWN, DEPRESSION IS LACK OF
CONTROL (Ervas, Gola and Rossi 2017), BAD IS DOWN and SAD IS DOWN (Kövecses 2010).

The fourth example in this set of conceptualizing postpartum depression via material object occurs in the same chapter. The speaker compares her experience of postpartum depression through the source domain of a 'cauldron'. As the speaker is meditating over her new situation, she starts to experience a feeling that she describes as "a cauldron boils in my mind" (Shafak, p. 212). Obviously, the speaker is talking metaphorically; she is not describing an actual cauldron, she refers to a mental state of an internal struggle that results from giving birth to her first child. She wants to communicate an abstract experience through a physical scenario. The term 'cauldron' serves as a source domain to reason about the negative state of postpartum depression. The speaker uses her prior knowledge of the cauldron to communicate her feeling of postpartum depression. Through cross-domain mapping, selected conceptual structured such as large metal pot, boiling stuff, fire and high temperature are mapped from the domain of the source domain of 'cauldron' onto the target domain of postpartum depression. The mapping process has contributed a new constructed meaning of the experience of postpartum depression; it has acquired new features that were not available before running the process. Thanks to the mapping process that it becomes possible to view an abstract state in a concrete way; as a boiling cauldron. The metaphorical expression "a cauldron boils in my mind" can be seen as a linguistic realization of the following conventional conceptual metaphors THE BODY IS A CONTAINER FOR EMOTIONS (Kövecses 2005), SADNESS IS A FLUID IN A CONTAINER (Kövecses 2010) and EMOTION IS A SUBSTANCE IN A CONTAINER (Kövecses 2005). The speaker extends these convention ways of thinking of emotions and abstract states to create his own metaphorical expressions.

The last example in this set of representation occurs when the speaker represents her postpartum depression in terms of 'blurry lenses'. The speaker states that "I had embraced depression to the point of seeing it as a permanent condition and looking at life through its blurry lenses" (Shafak, p.250). In this expression, the speaker draws a comparison between the target domain of negative state of postpartum depression and the source domain of 'blurry lenses'. Once again, the domain of physical object is used to conceptualize an abstract state; through the use of reification, the abstract notion of postpartum depression is materialized through the use of blurry lenses. The noun phrase 'blurry lenses' is used metaphorically in this extract, because the speaker is not referring to actual lenses that he wears; she speaks about an emotional or mental state that disturbs her vision. Due to the state pf postpartum 
depression, the speaker is unable to see things clearly, as if she looks through blurry lenses. The speaker uses her prior knowledge of the source domain to describe the target domain. The source domain of blurry lenses provides conceptual structures to reason about the abstract phenomenon of postpartum depression. By running the cross-domain mapping, the conceptual frames such as foggy, hazy, bleary, misty, cloudy and losing vision are mapped from the source domain of blurry lenses onto the target domain of postpartum depression. The outcome of the conceptual mapping has contributed a new meaning to the abstract state of postpartum depression. The negative state now can be viewed concretely as a physical object. The similarity between these two different domains is that, as looking through blurry lenses distorts one's vision, suffering from postpartum depression disturbs one's mental vision. The blurry lenses helps us to understand how postpartum depression is affecting the speaker's mental state; when postpartum depression strikes, the speaker's mental faculty stops functioning properly. This negative experience results in disturbing the speaker's mental vision. The linguistic metaphor above can be seen as a linguistic realization of the conceptual metaphors of DEPRESSION IS BLINDNESS, SADNESS IS BLINDNESS (Khajeh, Ho-Abdullah and Hua 2013) and EMOTIONAL HARM IS PHYSICAL DAMAGE (Kövecses 2010).

In Shafak's Black Milk, postpartum depression is also conceptualized as a sinister creature that is capable of causing harm to the speaker. This set of conceptualization contains two expressions. The first example occurs when the experience of postpartum depression is compared to "a Djinni in the room" (Shafak, p.223). Shafak, explicitly sets a comparison between her experience of postpartum depression and the mythical or supernatural creature; she calls him "the Djinni of postpartum depression" (Shafak, p. 225) who haunts new mothers. The context in which this expression is used is metaphorical for two reasons: first, postpartum depression is an abstract state, it is not a creature. The second reason relates to the fact that Djinni does not exist in reality. Therefore, the speaker is not talking literally, she is metaphorically comparing between two different entities, the abstract state of postpartum depression on the one hand, and the mythical creature of Djinni, on the other.

The speaker draws a physical description of this creature; she states that this creature is "not human, not animal, not like anything I have seen before. He is as dark gray as storm clouds, as tall as a tower, as elusive as a will- o'-the-wisp" (Shafak, p. 223). Since Djinni relates to the domain of diabolical being, it can be considered as a source domain that evokes many negative senses such as demonic, satanic, monstrosity, enmity and evil. It can provide more than one conceptual structure to the target domain of postpartum depression such as evil spirit, demons, devils, foe and enemy. This source domain evokes a physical scenario where a stereotypical sinister creature or a monster or a grim creature is targeting an agent and causing him/her physical harm. As a result of running the cross-domain mapping between the source domain of 'djinni' and the target domain of postpartum depression, the abstract experience of postpartum depression has acquired new features such as being horrible, fearful and horrific. The new meaning of postpartum depression is constructed as a sinister creature that is capable of performing an evil action upon the speaker. The physical scenario adds a sense of evil, fear and horror to the target domain of postpartum depression to emphasize the negative effect of this mental state. To create the linguistic expressions of "a Djinni in the room" and "the Djinni of postpartum depression", the speaker extends his knowledge of the conceptual metaphors of EMOTION IS OPPONENT (Kövecses, 2010: 108), SADNESS IS AN OPPONENT and SADNESS IS A CAPTIVE ANIMAL (Kövecses, 2000: 2526). These conceptual metaphors provide conventional experiences that shape the speaker's understanding of mental or emotional states. The similarity between the two compared domains is that both of them are associated with horror. As the presence of djinni may terrify and frighten people who are exposed to them, postpartum depression becomes a source of panic and trepidation for the speaker.

A similar representation occurs at the end of the novel when the experience of postpartum depression is conceptualized through another bizarre creature of an 'avid stalker'. Shafak states that "during that time, postpartum depression became an inseparable part of my life. Whenever I went, whatever I did, Lord Poton followed me like an avid stalker" (Shafak, p. 250). Lord Poton, in this extract, is the name of the Djinni that is already discussed above. This expression is clearly metaphorical because the speaker is not literally chased by a real stalker; she is describing a metaphorical chase. Literally, postpartum depression is not a creature to become a stalker; the speaker describes a negative mental state which becomes part of her daily life and takes away all the pleasure. In this expression, the abstract experience of postpartum depression is viewed through the source domain of 'avid stalker'. This source domain provides conceptual structure such as hunt, pursue, track, prowler that can be mapped onto the target domain of postpartum depression. After the process of cross-domain mapping is performed, the abstract notion of postpartum depression becomes seen concretely as an avid stalker that hunts a helpless victim to prey on. As a result of this metaphorical mapping, a physical scenario in which the speaker's postpartum 
depression corresponds to a baleful creature that threatens and menaces the speaker can be activated. The analogy between the two different domains is that, as a stalker keeps chasing its prey, the speaker's postpartum depression is inescapable. The metaphorical expression can be considered as a linguistic realization of the conceptual metaphors of EMOTION IS OPPONENT (Kövecses, 2010: 108), SADNESS IS AN OPPONENT and SADNESS IS A CAPTIVE ANIMAL (Kövecses, 2000: 2526).

The final set of representing postpartum depression is through the source domain of physical force. In this set, three metaphorical expressions will be examined to see how the speaker uses her prior knowledge of physical force to talk about an abstract phenomenon like postpartum depression. The first example of this group occurs in part two where the speaker compares her postpartum depression to a natural force (winds). She metaphorically names it as "winds of change" (Shafak, p.66). The expression "winds of change" can be seen as a metaphorical representation of the psychological state of postpartum depression. Due to her experience of this negative state, the speaker begins to notice a change not only in her behavior, but also in her psychology as well. The term 'winds', in this expression, serves as a source domain that allows us to understand the target domain (postpartum depression) in a better way. Through a process called cross-domain mapping, selected conceptual structures such as a destructive force, violent influence, change of direction and a sudden or complete turn are mapped from the source domain onto the target domain of postpartum depression. The cross-domain mapping allows the speaker to add new constructed features to the negative mental state of postpartum depression. These conceptual structures convey physical sensation by which the abstract experience of postpartum depression is communicated. The two separate domains (source and target) are juxtaposed in a way that they share common features; the speaker, metaphorically, points out a similarity between the two compared domains. For example, as winds force a change in the outer atmosphere, the experience of postpartum depression imposes an inner or psychological change on the speaker. The result of the cross-domain mapping is that, the abstract experience of postpartum depression becomes realized and understood concretely, i.e., a physical force that forcibly imposes change. For the speaker, having a postpartum depression is like being blown with a strong wind that disturbs or changes her inner calm. Thus, the linguistic expression "winds of change" can be considered as a linguistic realization of the following conceptual metaphors: DEPRESSION IS A HUGE PHYSICAL FORCE (Ervas, Gola and Rossi 2017) EMOTION IS A
PHYSICAL FORCE (Kövecses 2010), SADNESS IS A PHYSICAL FORCE (Kövecses 2000).

The second example is almost similar to the first where the experience of postpartum depression is conceptualized in terms of a storm. The speaker uses the expression "The calm after the storm" (Shafak, p.261) to comment on her experience of this negative mental state. The context in which this expression is said is metaphorical because literally, the speaker is not talking about an actual storm; she is describing an inner state that disturbs her mental peace. The term 'storm' is employed metaphorically, in this context, to stand for the negative mental state of postpartum depression. The association between this negative mental state and the storm are established through the effects both of these compared domains create. Conceptualizing postpartum depression as a physical force shows the intensity of this negative state on the speaker; it brings chaos to the speaker's life. This metaphor is used to depict a sense of mental confusion or fog which is suffered by the speaker as a result of postpartum depression. In this expression, the concept of 'storm' is used as a source domain to reason about the abstract state of postpartum depression. The speaker uses her prior knowledge of the source domain to communicate her experience of postpartum depression. Thus, selected conceptual structures such as violent disturbance, agitation and destructive outburst are mapped from the source domain of storm onto the target domain of postpartum depression. As an outcome of this cross-domain mapping, a new emerging meaning of postpartum depression is produced. The abstract notion of postpartum depression is understood through a physical scenario of a storm. The metaphorical expression "the calm after the storm" can be taken as a linguistic realization of the following conceptual metaphors DEPRESSION IS A HUGE PHYSICAL FORCE (Ervas, Gola and Rossi 2017) EMOTION IS A PHYSICAL FORCE (Kövecses 2010), SADNESS IS A PHYSICAL FORCE (Kövecses 2000).

The last metaphorical expression in this set occurs towards the end of the novel where the experience of postpartum depression is represented in terms of 'turbulence'. This expression is uttered in a conversation between Shafak and her husband. The husband remembers the days in which his wife was experiencing postpartum depression and comments "why didn't we ask for help from our families or friends while you were going through that turbulence" (p.261). In this expression, the term 'turbulence' activates a physical scenario in which an agent is affected by an external factor. The term 'turbulence' is used by speaker as a source domain to conceptualize the negative mental state of postpartum depression. The source domain of 'turbulence' provides conceptual structures such as 
commotion, agitation, irregular motion or violent or unsteady movement which are mapped onto the target domain of postpartum depression. The activation of cross-domain mapping results in creating a new meaning of this negative mental state; it has acquired new features that were not available before running the mapping process. As a result of this cross-domain mapping, postpartum depression can be viewed physically as a natural force characterized by up and down currents. The source domain of physical force helps us to understand abstract concepts such as postpartum depression in a coherent tangible way. The similarity between the two compared domains is that as turbulence causes an atmospheric change, postpartum depression causes an inner and psychological change. Again, the metaphorical expression above can be seen as a linguistic realization of the conceptual metaphors of DEPRESSION IS A HUGE PHYSICAL FORCE (Ervas, Gola and Rossi 2017) EMOTION IS A PHYSICAL FORCE (Kövecses 2010), SADNESS IS A PHYSICAL FORCE (Kövecses 2000).

The analytical investigation shows that the abstract experience of postpartum depression is represented through various ways by using different scenarios. For example, the experience of postpartum depression is compared to various experiences which belong to different domains that involve concrete and physical actions. Through conceptual mapping, the speaker is able to represent abstract qualities in terms of concrete objects. As a result of applying CMT it becomes possible to see such abstract notions like postpartum depression in a concrete and tangible way.

\section{CONCLUSION}

The paper provides a cognitive analysis of selected metaphorical expressions taken from Elif Shafak's Black Milk. The study mainly focuses on the way the experience of postpartum depression is communicated to readers through the use of conceptualization. Our study has approached the experience of postpartum depression cognitively. The cognitive framework shows that conceptual metaphor theory can be a useful tool to analyze the metaphorical representation of postpartum depression. Through cross-domain mapping, it becomes easy to understand abstract states through the help of physical and material experiences derived from other domains. In other words, conceptual mapping facilitates understanding notions of abstract qualities in terms of concrete objects and experiences. By using conceptual metaphors, it is possible to speak of complex and abstract states in a more concrete way. Selected conceptual structures are mapped from the concrete source domain onto the abstract target domain to make it more noticeable and easier to understand.
From the analysis above, we can conclude that since the experience of postpartum depression is an abstract phenomenon, the speaker (Shafak) relies on conceptualization to represent this negative mental state in a more familiar way. The intensity of postpartum depression is depicted through the interaction of various source domains. For example, the expressions we have analyzed in this study offer physical scenarios in which postpartum depression is compared to a physical location (place) such as: a sea without a shore, a quagmire, a roundabout of gloom and dark tunnel. Other expressions provide examples of representing postpartum depression in terms of physical objects such as: roller coaster, computer gone awry, sinking ship, cauldron and blurry lenses. The analysis also sheds light on conceptualizing postpartum depression through the source domain of sinister creatures such as: Djinni and avid stalker. We have also examined some expressions in which the negative state of postpartum depression is viewed through the source domain of physical force such as: storm, wind and turbulence. In all these examples, the speaker was presented as an agent under the influence of an external factor.

\section{REFERENCES}

Davison, Kenneth. 2006. 'Historical Aspects of Mood Disorders.' Psychiatry https://doi.org/10.1383/psyt.2006.5.4.115. 5(4):115-18.

Ervas, Francesca, Elisabetta Gola and Maria Grazia Rossi. 2017. Metaphor in Communication, Science and Education. Berlin: Walter de Gruyter GmbH \& Co KG.

Gibbs, Raymond. 2005. "Cognitive Linguistics and Metaphor Research: Past Successes, Skeptical Questions, Future Challenges." D.E.L.T.A. 22 (spe): 1-20. https://doi.org/10.1590/S0102$\underline{44502006000300003 .}$.

Górska,Elżbieta. 2019. Understanding Abstract Concepts Across Modes in Multimodal Discourse: A Cognitive Linguistic Approach. New York: Routledge, Taylor and Francis Group.

Goschler, Juliana. 2007. 'Metaphors in Cognitive and Neurosciences: which impacts have metaphors on scientific theories and models?' Metaphorik.de, 12, 1-20.

Khajeh, Zahra, Imran Ho-Abdullah, Tan Kim Hua. 2013. 'Emotional Temperament in Food-Related Metaphors: Across-Cultural Account of the Conceptualizations Sadness.' International Journal of Applied Linguistics \& English Literature 2 (6):54 -62. http://dx.doi.org/10.7575/aiac.ijalel.v.2n.6p.54.

Kövecses, Zoltan. (2005). Metaphor in Culture: Universality and variation. Cambridge: Cambridge University Press.

Kövecses, Zoltan. 2017. 'Conceptual Metaphor Theory'. In E. Semino, \& Z. Demjén (eds.), The Routledge Handbook of Metaphor and Language (pp. 13-27). London: Routledge.

Lakoff, Georg and Mark 1999. Philosophy in the Flesh: The Embodied Mind and Its Challenge to Western Thought. New York: Basic Books.

Lakoff, Georg and Mark Johnson 1980. Metaphors We Live By. Chicago: University of Chicago Press. 
Lakoff, Georg and Mark. 2003. Metaphors We Live By. Chicago: University of Chicago Press, 2003.

Murray, Lynne and Peter J. Cooper. 1999. Postpartum Depression and Child Development. New York: Guilford Press.

Petruck, Miriam. 2018. MetaNet. Amesterdam: John Benjamins Publishing Company

Pritzker, Sonya. 2003. 'The role of metaphor in culture, consciousness, and medicine: a preliminary inquiry into the metaphors of depression in Chinese and western medical and common languages.' Clinical Acupuncture and Oriental Medicine 4 (1): 11-28. https:// doi.org/10.1016/S1461-1449(02)00013-0.

Searle, John. 1979. 'Metaphor'. In Ortony. A. (ed.). Metaphor and Thought, first edition (pp.83-111). Cambridge: Cambridge University Press.

Semino, Elena and Zsófia Demjén. 2017. The Routledge Hand book of Metaphor and Language. London: Taylor \& Francis.

Semino, Elena. 2008. Metaphor in Discourse. Cambridge: Ca mbrid ge University Press.

Sfard, Anna. 1994. 'Reification as the Birth of Metaphor'. For the Learning of Mathematics 14 (1):44-55.

Shafak, Elif. 2007. Black Milk: On Motherhood and Writing. Translated by Hande Zapsu. New York: Penguin Group

Wikipedia contributors, "Postpartum depression," Wikipedia, The Free Encyclopedia,

https://en.wikipedia.org/w/index.php?title=Postpartum_depr ession\&oldid=962373567 (accessed June 18, 2020).

Zlatev, Jordan, Mats Andrén, and Marlene Johansson Falck. 2009. Studies in Language and Cognition. Cambridge: Cambridge scholars Publishing. 